\title{
Desiderio Navarro: Él respondía una postentrevista
}

\author{
Desiderio Navarro: \\ He Replied to a Post-interview
}

\author{
Margarita Mateo Palmer \\ Instituto Superior de Arte \\ Universidad de las Artes, Cuba \\ amateo@cubarte.cult.cu \\ orcid.org/oooo-0oo3-2177-0568
}

Resumen: El presente texto mezcla ficción y reflexión teórica para ofrecer un perfil colectivo de Desiderio Navarro como intelectual y como persona.

Palabras clave: Desiderio Navarro, Noches de Criterios, cultura cubana, Revista Criterios

Abstract: $\quad$ The present paper mixes fiction with theoretical reflection to offer a collective profile of Desiderio Navarro as an intellectual, and a person.

Keywords: Desiderio Navarro, Noches de Criterios, Cuban culture, Magazine Criterios

Recibido: $\quad 10$ de agosto de 2020

Aceptado: $\quad 30$ de octubre de 2020

De una conversación telefónica surgió la idea de realizar esta entrevista, no solo por escrito, sino de modo tal que el entrevistado tuviera la posibilidad de incluir preguntas que yo no le hubiera formulado inicialmente. La labor ciclópea - sí, ciclópea- desarrollada por Desiderio Navarro en el campo cultural cubano de las últimas décadas era inabarcable y temía dejar fuera cuestiones de especial interés. Convinimos entonces en que la conversación sería también un diálogo del autor consigo mismo, y él sugirió el término postentrevista para el futuro texto.

En ese espíritu de rebasar un diálogo inicial para enriquecerlo con una indagación posterior se fue conformando este intercambio. Su evocación de 
Ella escribía poscrítica - libro que incluye un capítulo de homenaje a Criterios- convocó a antiguos personajes de ficción.

Hasta aquí la introducción -y más adelante las preguntas- que mandé a Desiderio vía email y que nunca pudieron ser respondidas por el modo feroz y precipitado con que avanzó su enfermedad. La entrevista a cuatro manos, destinada a irse conformando a través de un juego de preguntas y respuestas — diga usted, responde tú; veo, veo ¿qué veo? - habría incluido, con toda seguridad, algunas variantes post no previstas. La idea de esa expansión poscrítica nos llenó, en aquel momento, de entusiasmo. Utilicé entonces las voces de algunos de los personajes de Ella escribía poscrítica para formular las preguntas: Dulce Azucena, sentimental y nostálgica; Surligneur-2, objetiva, racional; la Mitopoyética, apasionada por las leyendas y lo ficcional; y la Abanderada Roja, cuyo apelativo habla por sí mismo.

Retomo ahora ese texto inconcluso para tratar de llenar, de algún modo, los espacios vacíos, aunque sé de antemano que mi empeño es fallido pues nos falta — cuánto, cuánto- la voz principal. Sin embargo, en su lucha contra el olvido, la memoria puede apelar a las más diversas fuentes. Eso será lo que sucederá aquí con la intención de recuperar, aunque sea fragmentaria y oblicuamente, respuestas que nunca se escribieron.

Pregunta 1: Desde que comencé a pensar en esta entrevista, Dulce Azucena pidió la palabra. Ella, que guarda tan gratas memorias de los viajes a Camagüey durante su niñez, no me ha dado tregua desde entonces. Le doy, pues, la oportunidad de que te haga dos preguntas. La primera: ¿Qué recuerdos tienes de tu infancia camagüeyana?

Responde Desiderio con el fragmento de una entrevista:

Ese período inicial, sobre todo a partir de los seis años, fue, ante todo, el de la búsqueda de libros y la lectura incesante - primero de química, biología, psicología, filosofía y lingüística-. Fui un autodidacta nato: un día mis padres descubrieron que había aprendido a leer solo, y desde entonces estimularon en mí el estudio y procuraron mi desarrollo intelectual en la medida de sus limitadas posibilidades económicas. Mi mejor regalo de Reyes Magos fue un escritorio hecho por mi papá en calidad de Melchor, Gaspar y Baltasar (León 2017: 4). 
En la papelería dejada por Desiderio aparecieron varios poemas inéditos, escritos en su juventud. Algunos fragmentos de uno de ellos - "Misterios del oficio", dedicado a su padre - pueden, de algún modo, responder también a Dulce Azucena:

Mientras con piedras, trompos y animales

Jugaba yo todo el bendito día,

Mi joven padre límpidos metales

Duro golpeaba hasta que los vencía;

Duro golpeaba y no sin alegría,

Como si allí golpeara sus tristezas,

Nací hojalatero, me decía,

Mientras sacaba chispas a las piezas.

A veces me mostraba sus riquezas:

Tenazas, limas grandes, pequeñitas,

Pinzas, un soldador, llaves inglesas,

Cada cual con virtudes inauditas.

$[\ldots]$

Cada metal tenía leyes raras

La frágil calamina, el cobre oscuro,

El rarísimo aquel de planchas caras,

El duro acero-níquel, el zinc puro.

\section{$[\ldots]$}

Un día, con voz libre de artificio, Me confesó con rostro muy sincero:

-Este trabajo fue mi mayor vicio, Obrero soy, y tú hijo de obrero. Todo se lo debemos a mi oficio, Desde los dieciséis: hojalatero.

\section{$[\ldots]$}

No pasa hoy junto al horno el día entero Y su trueno en la memoria ya es murmullo. 
De su vejez recuerdos salvar quiero,

De cuando por oficio quise el suyo.

Mi padre me enseñó a cortar acero.

Ser buen hojalatero era su orgullo.

Responde Joyce Navarro:

Hijo de hojalatero y de ama de casa, mi papá, con cuatro años ya leía y escribía correctamente; se refugió — por la poca atención que le podían brindar sus padres, mi abuela se dedicaba a la costura para ayudar en la economía de la casa y mi abuelo llegaba muy tarde de los ferrocarriles - en los libros y cómics que llegaban a sus pequeñas manos, y aprendió, de esa manera, a leer solo. En la televisión, con los muñequitos americanos que se transmitían en ese entonces, fue aprendiendo a hablar inglés.

Como a cualquier niño de su edad, le gustaban los juegos y el ir de vacaciones a la Playa de La Jibara — donde disfrutaba junto a su padre del arte de la pesca-, pero siempre se las arreglaba para tener un libro en sus manos. Mis abuelos, al ver el despuntar de su inteligencia, decidieron hacer un esfuerzo y pagarle una de las mejores escuelas privadas de Camagüey, el Colegio Pirson, para que realizara sus estudios primarios. Allí se destacó por su aplicación e inteligencia, sobre todo en las ciencias, principalmente en la química, su preferida. Con nueve años, por su asombrosa facilidad en la adquisición de conocimientos de química, una profesora de dicho colegio lo llevó al Instituto de Segunda Enseñanza y habló con un profesor de esta materia para que le realizara un examen. El profesor lo incorporó junto a sus alumnos de segundo año a un examen ordinario, y al comprobar el resultado obtenido por Desiderio, exclamó: "Este niño es un prodigio". Cabe decir que la calificación fue de 100 puntos, nota que ninguno de los alumnos había obtenido por el rigor que aplicaba este profesor en sus evaluaciones.

Para aquel entonces, su lugar preferido era un buró hecho por su padre, donde tenía armado un pequeño laboratorio químico que le permitía realizar sencillos experimentos - alguno tenía un final exitoso y otros terminaban con una pequeña explosión y su cara, negra-. Pero no todo era color de rosa para él; de cierta manera, se sentía discriminado, no solo por ser el raro de la escuela, sino también por pobre, ya que su uniforme no era comprado sino cosido por su madre costurera y era poco el dinero que le podían dar para meriendas. 
Pasada esta primera etapa, mi papá realizó sus estudios de enseñanza superior - como entonces eran llamados el séptimo y octavo grados- estudiando solo en su casa y presentándose a los exámenes: venció las asignaturas de bachillerato en solo tres años, en lugar de cinco. Sin la edad requerida, y ya con la Revolución en el poder, su mamá escribió una carta de petición al Ministro de Educación doctor Armando Hart, para solicitar el ingreso del niño de 15 años a la universidad. Este permiso le fue otorgado, y de esta manera logró matricularse en Química en la Universidad Central, donde permaneció dos años. Abandonó dicha institución, no por desmotivación, sino porque el programa de estudios no le permitía avanzar en sus conocimientos. Aún sin edad laboral, trabajó como profesor de Química en la Secundaria Básica del Central Céspedes, en el municipio de Florida; ya para ese entonces mostraba su pasión por la literatura, y escribió sus primeros poemas. Casi a la par, creció su interés por el cine y el teatro. Le apasionaba mucho la fotografía, y no solo se limitaba a observar a través del lente, sino también las imprimía en un pequeño cuarto de fotografía que su padre le ayudó a crear.

En el año 1965, mi papá ingresó a la Escuela Nacional de Artes para estudiar Dirección Teatral, pero al no haber profesores de esta especialidad tuvo que matricular Actuación. Por esa época, también ejerció de manera voluntaria como profesor de Química de los alumnos de Pre de esta escuela. Al año, abandonó la ENA regresando a su tierra natal y comenzó a trabajar como asesor literario del Conjunto Dramático de Camagüey. En esa etapa ganó un premio provincial en cuento y participó en el concurso 26 de julio en cuento y poesía, y ganó premios en ambos géneros.

Pregunta 2: Insiste Dulce Azucena: dicen que en distintos textos de autores camagüeyanos El Casino Campestre aparece como un espacio recurrente, casi mítico. ¿Para ti también tiene un significado especial este parque situado al costado del Instituto de Segunda Enseñanza donde estudiaste?

Cuando le hice esta pregunta a Desiderio, yo no conocía "Noche de San Juan" -el cuento que ahora va a dar parcial y tangencial respuesta a Dulce Azucena-, escrito en 1967 y publicado en La Gaceta. En este relato sobre la lucha insurreccional de los jóvenes en la ciudad de Camagüey, tiene un papel privilegiado el Casino Campestre, donde se desarrolla la mayor parte de la acción. Describe el narrador en tercera persona: 
Y parece que llegan al Casino para llenar sus bancos: alumnos del Instituto con carpetas y libretas y camaritas fotográficas, billeteros a descansar, desamorados cónyuges con sus amantes, nerviosas parejas de novios. Y para refrescarlos a todos también llegan: vendedores de pru oriental, granizaderos, heladeros Cory, Guarinas y de barquillo. [...]

Más adelante:

Y parece que llegan al casino para estrenar el sol y la sombra de los árboles, los bancos, los bebederos, la gruta de la glorieta y los aparatos de diversión: escolares blanquiazuliuniformados en pequeñas risas, riñas y bombochías, niños y niñas montados en carriolas, velocípedos, patines y bicicletas, con pelotas y guantes, revólveres y espadas, en carreras, batallas y series de baseball. ${ }^{1}$

Pregunta 3: ¡Ay, Desiderio! Hace poco la Mitopoyética escuchó a un cineasta español de paso por Cuba, hablando maravillado por un personaje alucinante llamado Desiderio Navarro que traducía textos teóricos de 20 idiomas diferentes. Apenas lo podía creer. Lectora incansable de sor Juana, la Mitopoyética recordó entonces un poema en el que la monja mexicana, abrumada por el asombro que causaban su sapiencia y su talento, escribía: "Qué dieran los saltimbanquis / a poder por agarrarme / y llevarme como a un monstruo / por esos andurriales”. Ella te pregunta: ¿Has tenido alguna vez una sensación similar? Dile, Desi, por favor.

Responde Desiderio al sesgo, con un fragmento de la entrevista ya citada:

El traducir múltiples lenguas es la parte menos importante de mi trabajo, pero es lo que yo llamo la parte "circense", "malabarística”, la que llama la atención y que, lamentablemente, alguno que otro utiliza para desviar las miradas de lo más importante de esta faceta divulgativa de mi labor: el rigor del trabajo de investigación, lectura y selección practicado en el oceánico pensamiento mundial sobre las más diversas disciplinas, artísticas y culturales. También esa labor de divulgar traducciones propias y ajenas de textos valiosos comenzó en Adelante, cuando publiqué un artículo sobre el surrealismo del destacado crítico francés José Pierre, miembro del Grupo Surrealista (León 2017: 4).

1 El cuento fue encontrado como un recorte en su papelería, que Tatiana Gorstko, su viuda, gentilmente me permitió consultar. No han podido encontrarse los datos precisos del número de La Gaceta donde fue publicado. 
Pregunta 4: Toma la palabra Surligneur-2: ¿Cómo se inició tu relación con Iuri Lotman? ¿Cuáles fueron las impresiones del sabio estonio cuando visitó Cuba?

Responde Tatiana Gorstko, su viuda:

El interés de Desiderio por la semiótica en general y por la obra de Iuri Lotman y sus colaboradores de la Escuela de Tartu surgió mucho antes de su encuentro personal con este famoso científico. El mejor testimonio de la importancia que él concedía a su promoción en Cuba y en otros países de habla hispana son las numerosas traducciones de sus obras publicadas en la revista Criterios y el encuentro organizado en su centro. Pero este tema exige todo un estudio aparte y un especialista en semiótica. Yo me concentraré en las relaciones personales entre Desiderio y Iuri Mijáilovich, y los aspectos de la vida y obra de este que resultaban de su mayor interés y admiración, y que contribuyeron a su colaboración y amistad.

Por primera vez nos encontramos con Iuri Lotman en la Biblioteca Lenin de Moscú, y los dos nos quedamos cautivados por su sencillez y cordialidad, tan inesperada en una persona famosa en toda Europa. Lo primero que le impresionó a Lotman de Desiderio fue lo que impresionaba a todo el mundo: un hombre orquesta. Lo primero que le impresionó a Desiderio de Lotman fue lo que impresionaba a todo el mundo desde el primer momento: su bondad y generosidad, su afán de apreciar a cualquier estudioso, no por su cargo o grado científico sino solo por sus conocimientos y su talento creador. Lotman le entregó a Desiderio numerosos escritos suyos para su publicación sin hablar siquiera del cobro de los derechos de autor. Más aún, le cedió los derechos para publicar sus artículos de Semiótica de la cultura. Él no escatimó tiempo a la hora de ayudar a resolver problemas que solían surgir en el curso de la traducción. Lo que más emocionaba a Desiderio era que esta generosidad no provenía de la abundancia, sino de la escasez. Según los amigos íntimos de Lotman, esa famosa generosidad unida a su no menos famosa hospitalidad conducía a que, aún en la época de mayores ingresos, Lotman, a menudo, andaba falto de dinero y hasta endeudado. En cuanto a su tiempo, cuando me enteré por diferentes fuentes del volumen de trabajo que él realizaba a diario, me preguntaba si le quedaba tiempo aunque fuera para dormir.

Pero lo que más unía a Desiderio con Lotman era que los dos profesaban los mismos principios éticos del trabajo científico: libertad de pensamiento, negación de la existencia de un conocimiento final, necesidad de una discu- 
sión libre para establecer una verdad científica, discusión donde deberían utilizarse solo los argumentos científicos y no una presión autoritaria o acusaciones políticas. Seguir estos principios costaba caro. Desde sus inicios en los años sesenta, la labor de los semióticos soviéticos a menudo parecía un campo de batalla. Continuos chequeos en la cátedra de Lotman, el registro policial en su propia vivienda, la lucha por publicar los materiales, reducidas tiradas, y aún más reducida publicidad. En estas condiciones tenían que trabajar a menudo muchos científicos de la Escuela de Tartu y el propio Lotman. No es de asombrase que Desiderio estuviera convencido de que las autoridades soviéticas no permitían la entrada de los extranjeros a Tartu a causa de esa Escuela. Me parece más bien que la razón era la presencia ahí de una fábrica militar, pero creo que las sospechas de Desiderio tenían su fundamento.

Pero los libros, gracias a la pujanza de los autores, a pesar de todo, se difundían y ganaban prestigio. Cualesquiera que fueran las tiradas, gracias a su valor científico, los libros de Lotman, Torop, Toporov, Yampolski, para solo citar algunos, volaban de los mostradores al instante. Cuando empezamos a buscarlos en Moscú tuvimos que sustituir la palabra comprar por la palabra conseguir. Salvo rarísimas excepciones, tuve que fotocopiar los materiales en las bibliotecas o pedirlos a los autores.

Creo que mucha gente oyó a Desiderio decir "no hay profeta en su tierra". Es perfectamente aplicable a Lotman: siendo ya un científico famoso en toda Europa y América, y miembro de las Academias de Ciencias inglesa y noruega, no fue aceptado como miembro en la Academia de Ciencias de Estonia y aunque ingresó a esta unos años más tarde, nunca pudo ser miembro de la Academia de Ciencias de la URSs.

En sus últimos años de vida, Lotman pudo por fin salir al extranjero. Entre otros países, visitó Cuba. En la actividad organizada por Criterios, él esperaba tener un contacto directo con los científicos cubanos, un intercambio de ideas dentro de un diálogo abierto que él, desde los tiempos de las famosas Escuelas de Verano, consideraba una de las formas más productivas y fructíferas del desarrollo científico.

Conociendo la vida de Iuri Mijáilovich, como Desiderio la conoció, él seguramente estaría de acuerdo con las palabras pronunciadas por el presidente Lennart Meri en el almuerzo funerario del gran científico: "Hoy hemos enterrado a Iuri Lotman y no sé si alguien nacido hoy podrá convertirse en un nuevo Iuri Lotman dentro de algunos años. Yo solo quisiera esperar que en 
esta República Estonia que estamos construyendo, la autorrealización de los futuros Iuri Lotman sea más sencilla de lo que resultó para él mismo". ${ }^{2}$

No pretendo en modo alguno afirmar que el valor de Desiderio como científico es igual al del eminente estudioso, pero me gustaría pensar que en su vida creadora Desiderio siguió el ejemplo de este gran sabio y excelente persona. Parafraseando a Stanislavski, ambos amaban la ciencia en sí mismos, y no a sí mismos en la ciencia. Esto les daba fuerzas para luchar por sus ideas, vencer las dificultades conservando el humor y el optimismo, y, lo más importante, trabajar, trabajar y trabajar. Ni siquiera una gravísima enfermad, ni la proximidad de la muerte los pudo hacer bajar los brazos. No. Los animó a trabajar más rápidamente para poder hacer, aunque fuera, un poquitico más.

Pregunta 5: Continúa Surligneur-2: A pesar del tiempo y la energía que ha demandado de ti Criterios - un proyecto descomunal que has mantenido contra viento y marea seleccionando, traduciendo, mecanografiando, editando, diseñando, yendo a las imprentas, cargando tú mismo las cajas de libros, divulgando las actividades, vendiendo los ejemplares y un etcétera interminable-, has podido encontrar un pequeño espacio para tu propia obra. ¿Cuál de los libros de ensayo que has publicado te resulta más entrañable y por qué?

Respuesta abierta. Haré una brevísima mención de los cuatro libros. Cada lector responderá esta pegunta de manera individual, según sus propias preferencias:

1. Cultura y marxismo. Problemas y polémicas. Letras Cubanas, 1986. Edición: Ángel Fernández Guerra. Dedicatoria: "A Hilda y Desiderio, por la vida. A Joyce y Rashid, por su infancia. A Tatiana, por nuestro hogar".

2. Ejercicios del criterio. Unión, 1988. Edición: José Rodríguez Feo. Sin dedicatoria, ni exergos.

3. Las causas de las cosas. Letras Cubanas, 2006. Edición: Rinaldo Acosta. Sin dedicatoria. Exergos: "Feliz el hombre que puede llegar a cono-

2 Las citas y los datos biográficos de I. Lotman fueron tomados del libro de Borís Fiódorovich Egórov, Zhizn' i tvorchestvo Yu. M. Lótmana [Vida y obra de Iuri Mijáilovich Lotman], Moscú, Nóvoe Literatúrnoe Obozrenie, 1999. 
cer las causas de las cosas". Virgilio: Geórgicas; "En realidad la actitud crítica es la única productiva, la única digna del hombre. Significa colaboración, desarrollo, vida”. Bertolt Brecht.

4. A pe(n)sar de todo. Para leer en contexto. Letras Cubanas, 2007. Edición: Rinaldo Acosta. Dedicatoria: "A la memoria de Carlitos Victoria, por su amistad y por su decisivo aliento inicial en el Camagüey de los 6o". Exergos: "Conocer diversas literaturas es el medio mejor de liberarse de la tiranía de algunas de ellas". José Martí; "Verde, querido amigo, puede ser la teoría cuando está gris el árbol de la vida”. Mefistófeles. Fausto, de Goethe, 1968.

Pregunta 6: Turno de la Abanderada Roja: Desde hace algunos años has ido publicando reflexiones de importantes pensadores acerca de la caída del campo socialista y la situación posterior en los países de Europa del Este. ¿Qué importancia concedes a la divulgación de esos textos en la isla?

Cito un fragmento de su "In medias res publicas: Sobre los intelectuales y la crítica social en la esfera pública cubana”:

La suerte del socialismo después de la caída del campo socialista está dada, más que nunca antes, por su capacidad de sustentar en la teoría y en la práctica aquella idea inicial de que la adhesión del intelectual a la Revolución -como, por lo demás, la de cualquier otro ciudadano ordinario- "si de veras quiere ser útil, no puede ser sino una adhesión crítica”; por su capacidad de tolerar y responder públicamente la crítica social que se le dirige desde otras posiciones ideológicas - las de aquellos "no revolucionarios dentro de la Revolución", a quienes se refería la célebre máxima de 1961—; por su capacidad, no ya de tolerar, sino de propiciar la crítica social que de su propia gestión se hace desde el punto de vista de los mismos principios, ideales y valores que proclama como propios, esto es, de ser el mecenas de la crítica socialista de su propia gestión; en fin, por su capacidad de asegurar que el intelectual, para publicar la verdad, no tenga que apelar al "samizdat" o al "tamisdat", 3 esferas públicas diaspóricas y otros espacios culturales y mecenazgos

3 Tamizdad, neologismo ruso, construido por analogía con samizdata partir de tam ('allá') e izdat (apócope de izdatelstvo, 'editorial'). Designa las ediciones norteamericanas, euroccidentales, etc., de textos de autores soviéticos y de otros países del bloque socialista que, por decisiones gubernamentales, no podían ser publicados en sus respectivos países de origen ( $N$. del A.). 
extraterritoriales, ni vencer las "dificultades al escribir la verdad" señaladas por Brecht en su célebre artículo de $1935^{4}$ (Navarro 2006: 30).

Pregunta 7: Fiel a su vocación profesoral, Surligneur-2 les pregunta a sus estudiantes qué preguntas te harían si estuvieras delante de ellos. No puedo incluirlas todas aquí. Selecciono la más reiterada, en alguna de sus variantes: ¿Cómo surge la idea de los Mil y un textos en una noche? ¿Qué tiempo lleva crear esta compilación? ¿Por qué hacer las Noches de Criterios?

Responde la propia entrevistadora:

No recuerdo exactamente cuando comenzaron a celebrarse los Mil y un textos en una noche, pero, según me comenta Joyce, Desiderio comenzó a compartir los textos que consideraba de interés cuando aún se utilizaban disketes para copiar la información. Luego se pasó a la modalidad de CD-ROM y, por último, se utilizaron las memorias. Las primeras actividades eran muy demoradas debido a la lentitud de las máquinas en el proceso de transferir los datos. No obstante, los interesados, que eran muchos, esperaban pacientemente hasta obtener su copia de los textos seleccionados por Desiderio. No puedo imaginarme el tiempo que le llevaba la búsqueda, recopilación y ordenamiento de aquellos cientos de trabajos de pensadores de diferentes partes del mundo, como tampoco he podido nunca imaginarme cómo Desiderio lograba aprovechar el tiempo hasta límites que parecían sobrehumanos. Los Mil y un textos en una noche tuvieron cinco entregas. En la primera Desiderio explica, en una especie de prólogo titulado "Por la circulación internacional de las ideas":

Ante la sostenida y casi absoluta ausencia de las principales figuras del pensamiento internacional sobre las artes y la cultura en nuestras publicaciones, librerías, bibliotecas y eventos, y en la imposibilidad de divulgar de otro modo el extraordinario volumen de pensamiento cultural trabajosamente recopilado por Criterios en su batalla por el acceso a las ideas para los investigadores, críticos, profesores, estudiantes, creadores y cuadros cubanos en esos dominios, en la noche del viernes 2 de noviembre del 2007 el Centro Teórico-Cultural Criterios ofreció, en su sede, la posibilidad de copiar gratuita y libremente mil y un textos teóricos en archivos electrónicos en formato PDF. En el encuentro titulado Los mil y un textos en

4 Bertolt Brecht, "Fünf Schwierigkeiten beim Schreiben der Wahrheit" (1935), Schriften zur Literatur und Kunst, Aufbau-Verlag, Berlín y Weimar, 1966, tomo I, pp. 265290. 
una noche, a cada uno de los cientos de asistentes que desfilaron por cinco horas, se le copiaron en sus dispositivos de almacenamiento electrónico trabajos que escogió de la lista de variados artículos, capítulos de libros y libros completos que se hizo circular con anticipación.

Dado que el Centro aún no ha podido abrir en su sede la Biblioteca Salvador Redonet Cook, la cual, de todos modos, sería de difícil acceso a los interesados de otras provincias, hemos decidido preparar y distribuir nacionalmente un CD que contiene la primera de una serie de recopilaciones titulada

Los mil y un textos en una noche

Este primer volumen encierra una versión corregida y mejorada del conjunto de archivos digitales ofrecidos en el mencionado encuentro de igual título: 1001 textos escogidos —en español, inglés, francésy portugués-, obras actualesy clásicas de pensadores de América del Norte, América Latina, Europa Occidental y Oriental, Asia y África, que desde muy diversas posiciones abordan los más variados problemas de

teoría de la literatura, las artes plásticas, el teatro, el cine, la música, la danza y la televisión, teoría del arte y estética, sociología, antropología y semiótica de la cultura, filosofía y pensamiento social, estudios culturales de género, de raza, lesbianos/gay/queer (2007).

Las Noches de Criterios comenzaron, con ese título, cuando ya el Centro tenía su local propio en la sede del ICAIC (Instituto Cubano de Arte e Industria Cinematográficas), pero en realidad son continuidad de las actividades que Desiderio había venido desarrollando desde antes y que contaron con la presencia en Cuba de relevantes teóricos a nivel mundial como Frederic Jameson, Iuri Lotman, Jonathan Culler, Viacheslav Ivanov, Patrice Pavis, Pierre Dubois, Jochen Schulte-Sasse, Gerald Prince o Manfred Pfister, que impartieron charlas y conferencias convocadas por la revista. Las Noches de Criterios contaron con la participación de pensadores como el mismo Manfred Pfister, Boris Groys, Nicolas Bourriaud, Wolfgang Welsh, Ana María Guash, Hans-Thies Lehmann o Erika Fischer-Lichte. Esos encuentros también contemplaban paneles sobre temas de interés, presentaciones de libros y ventas de la revista.

Responde Modesto Milanés:

Saber cómo surgió la idea de los 1001 textos en una noche resulta cosa poco menos que imposible, pues solo Desiderio Navarro hubiera podido dar una 
respuesta precisa a esa pregunta. En algún momento de su incansable tarea como traductor y gestor cultural, Desiderio pudo haber notado que la disponibilidad de textos teóricos en español y otros idiomas era mayor que la posibilidad real de seleccionarlos y reunirlos en libros o en revistas, por muy rigurosas que fueran esas antologías. También vale señalar que un sector muy grande de los consumidores de Criterios y otras publicaciones que generaba el Centro eran estudiantes de la Facultad de Letras y del Instituto Superior de Arte (ISA), muchachos que por su edad y su formación eran lo que podría llamarse "nativos digitales" (es decir, personas más familiarizadas con la lectura de PDF en laptops y teléfonos celulares, que con los libros impresos). A las dos razones apuntadas hay que agregar una tercera, y es el extremo nivel de especialización que distingue los estudios de teoría y estética en nuestros días, lo que hace que muchas veces un libro recién impreso ya sea prácticamente obsoleto frente a otros puntos de vista aparecidos en los predios del riguroso y cambiante mercado teórico del arte. Entonces, y ante la perspectiva de lo mencionado arriba, quizá Desiderio tuvo la feliz idea de convocar a esos encuentros; encuentros donde se ponía a disposición de un público ávido y heterogéneo (estudiantes, investigadores literarios, críticos, lingüistas, profesores, artistas plásticos, cineastas, editores, escritores), no solo todo lo que estaba disponible y libre de derechos en el ámbito académico de muy diversas disciplinas, sino que también se ofrecía lo más reciente, lo más novedoso en esos campos.

Por otra parte, los encuentros que generaban las actividades del Centro Criterios (ventas de libros y revistas, ciclos de conferencias, descarga de textos) no solo representaron la adquisición de libros y otros materiales, o la obtención de información novedosa en ciertas esferas o campos de la teoría o la estética. Fue, ante todo, la expresión de un clima intelectual y profesional sumamente rico; de un fervor por el conocimiento y las cuestiones de la teoría de la cultura que nunca más se repitió de la misma manera después de aquellos años. Mirando aquel tiempo con la ventaja que da la perspectiva de lo pasado, puede afirmarse sin temor que la impronta de Criterios, lo que significó en el orden de la cultura, fue algo muy importante, porque funcionó como una universidad alternativa, un mundo y unas opciones de saber que completaban, que llenaban un espacio vacío. Fue, en suma, la materialización de una empresa increíble llevada adelante por la tenacidad y los talentos de una sola persona. Una empresa y un hombre de extraordinaria generosidad, porque no solo se trata de un hombre que dedicó todas sus fuerzas y talentos al servi- 
cio de los demás, sino que el resultado de ese esfuerzo tan grande y complejo - libros y revistas cuidadosamente seleccionados, traducidos y editadosse vendía por un precio bajísimo, irrisorio, casi simbólico. Al cabo de tantos años, todavía recuerdo con agradecimiento las tantas veces que Desiderio, al ver mis pocos dineros estudiantiles, me regaló las publicaciones de Criterios.

Responde finalmente Desiderio, oblicuamente, con un fragmento de la entrevista citada:

A diferencia de tantos que, cuando, en medio de nuestras carencias informativas nacionales, consiguen un libro valioso del extranjero, lo usan, lo citan, pero lo mantienen "enguacalado" en su casa, yo no soporto la sensación de estar leyendo un texto importante, interesante, sea en español y, más aún en otro idioma, mientras a mi alrededor críticos, investigadores, profesores, estudiantes y otros interesados en el tema no tienen acceso a este. Y me duele no tener más tiempo para darle a tanta gente todo lo extraordinariamente valioso del pensamiento teórico cultural mundial que desconocen y necesitan, cada vez más (León 2017: 4).

\section{Bibliografía}

Brecht, Bertolt (1966 [1935]). "Fünf Schwierigkeiten beim Schreiben der Wahrheit", Schriften zur Literatur und Kunst, Berlin/Weimar, Aufbau-Verlag, tomo I.

Egórov, Borís Fiódorovich (1999). Zhizn'i tvorchestvo Yu. M. Lótmana [Vida y obra de Iuri Mijáilovich Lotman], Mockbá, Nóvoe Literatúrnoe Obozrenie.

LEón, Yanetsy (2017). "Desiderio Navarro: la pasión por compartir el conocimiento", La Gaceta de Cuba, núm. 5, setiembre-octubre: 4.

Navarro, Desiderio (2006). Las causas de las cosas. La Habana, Editorial Letras Cubanas.

Navarro, Desiderio (2007). Los mil y un textos en una noche. Volumen I. La Habana, Centro Teórico-Cultural Criterios, edición digital, nov.

\section{Margarita Mateo Palmer}

Ensayista, narradora y profesora. Doctora en Ciencias Literarias por la Universidad de La Habana. Miembro de número de la Academia Cubana de la Lengua y correspondiente de la Real Academia de la Lengua Española. Fue profesora de la Facultad de Artes y Letras de la Universidad de La Habana (1974-200o) y del Instituto Superior de Arte, del que actualmente es profesora consultante. 
Entre sus libros más importantes se encuentran: Ella escribía poscrítica (1995), Paradiso: la aventura mítica (Premio Alejo Carpentier, 2002), El Caribe en su discurso literario (en coautoría con Luis Álvarez, Premio al Pensamiento Caribeño 2002-2003 otorgado por la UNESCO y el Estado de Quintana Roo) y Desde los blancos manicomios (novela, Premio Alejo Carpentier, 20o8). Ha obtenido en siete ocasiones el Premio Nacional de la Crítica Literaria. Es Premio Nacional de Literatura 2016. 